\title{
Research on Hardware Structure of Intelligent Accompanying Tool Car in Dispatching Automation Computer Room
}

\author{
Li Sun ${ }^{1}$, Tianquan $\mathrm{Li}^{1}{ }^{*}$, Dayong Liu ${ }^{1}$, Daliang Wang ${ }^{1}$, Yufei Song ${ }^{1}$, Xiaohang Liu ${ }^{1}$, Xudong Cao ${ }^{1}$ and Yu Shi ${ }^{1}$ \\ ${ }^{1}$ State Grid Changchun Power Supply Company, Changchun 130021, China
}

\begin{abstract}
Aiming at the problems of complicated equipment types, low work efficiency in the computer room and safety management of the whole work process in the current dispatching automation computer room, the research on the intelligent companion tool cart with the management function of tools and equipment is proposed.Through the hardware research on the overall structure of the tool trolley according to the needs of the machine room work, the design and development of a three-layer intelligent companion tool trolley provides a self-cleaning operation platform for the maintenance staff of the automated machine room. Afterwards, hardware researches on sensors, communication interfaces, toolboxes, and power supplies were carried out.The power supply conducts hardware research, designs the management method of radio frequency scanning tools, and realizes the management of necessary tools and common spare parts for maintenance in the computer room. At the same time, it automatically accompanies and tracks the whole process of video recording, and realizes the safety control and intelligent management of tools and tools for debugging special laptops, which provide a basis for future software design.
\end{abstract}

\section{Introduction}

Nowadays, with the rapid development of computer technology, automatic control technology, sensor technology, communication technology and artificial intelligence technology in multiple disciplines, the types and quantities of network equipment, servers and application systems continue to grow.It also poses new challenges to the internal business operation and management mode of the automation system.[1,2]At this stage, the construction of the dispatch network enables the current and future dispatch automation systems to realize network interconnection and data sharing between various dispatch automation systems and all levels of dispatch automation systems, and the connection will become closer and closer. While this change brings a lot of sharing information and work convenience, the availability and security requirements of network equipment, application systems, computer room environment and servers are also increasing.[3]At present, the patrol management of the dispatching automation computer room is mainly done manually. In the face of increasing hardware equipment and stricter network security requirements, the daily work mode of the dispatching automation computer room should also usher in new changes.

\section{Background and significance}

With the continuous development of the power grid, the equipment of the master dispatching automation station continues to increase. There are many system servers and equipment running in the automation room of the power dispatching control center. The normal operation of these systems is directly related to the normal monitoring and data collection of the power grid, and is an important guarantee for the safe production of the power grid.With the continuous increase of various systems and equipment in the automated machine room, improving the efficiency of equipment operation and maintenance and safety management in the machine room has become an important issue.[4]

a) There are many types of equipment and interfaces involved in the work of an automated computer room, and many tools and instruments are required. There are often problems such as loss of special interface lines and failure of tools and appliances.

b) Workers generally sit or squat on the ground to work, and there is no operating platform. This working method has high work intensity and is not easy to operate, which directly reduces the work efficiency in the computer room.During the working process, the tiny bare thread ends are not easy to clean, which may cause machine failure.

c) The special debugging software and debugging line required for debugging network equipment and safety protection equipment lack safety management and control means, and it has not realized the debugging of notebook computer operation records and screen recording. The fixed video surveillance equipment in the computer room cannot effectively and accurately record the entire work process of the staff, and cannot realize the safety management of the entire work process.

d) The maintenance of laptop computers does not

\footnotetext{
*Tianquan Li: 806306063@qq.com
} 
realize the special purpose of partitions, which does not meet the requirements of the State Grid Corporation's urban power grid safety evaluation.

Carrying out research on intelligent management of operation and maintenance of dispatching automation computer room, and making an intelligent companion tool cart for automation computer room can effectively solve the above problems and provide automatic computer room maintenance personnel with self-cleaning operation desks, necessary tools and tools for computer room maintenance, and common spare parts. At the same time, it can automatically accompany and track the whole process of recording and recording, and realize the functions of debugging special laptop safety control and intelligent management tools. Improve the efficiency and quality of automated maintenance equipment, strengthen the safety management and control of computer room maintenance, and provide a strong guarantee for the company's safe production.

\section{Status and problems to be solved}

There are related products in domestic automated information room inspection robots, management robots, etc. There are many published documents and the research methods are relatively mature.However, automated information computer room inspection robots are limited to functions such as equipment indicator lights, computer room environment, security, and personnel access management.[5,6]In substations, there are many functions developed by robots, such as patrolling and collecting information.[7-9]However, there is a big difference between the dispatching automation machine room and the substation equipment. In view of the working characteristics of the automation machine room, no robots and other equipment with very suitable functions have been developed at this stage.

According to the above-mentioned series of problems existing in the current dispatching automation machine room, the intelligent companion tool cart is introduced, and all functions are integrated on the self-cleaning console that is convenient for the staff to use.Through intelligent accompaniment, provide self-cleaning operation table, necessary tools and equipment for computer room maintenance work, and common spare parts for maintenance staff of automated computer room.At the same time, it can automatically accompany and track the whole process of recording and recording, and realize the functions of debugging special laptop safety control and intelligent management tools.It fills the gap in the safety management of computer room maintenance work and meets the safety evaluation requirements of urban power grids.

\section{Hardware realization and analysis of tool cart}

\subsection{Research on the overall structure of tool carts}

The intelligent companion tool cart is designed to integrate various functions and is designed according to a three-layer structure. The lower layer is an intelligent robot base with a load of $80 \mathrm{~kg}$; the tool cart base is equipped with a large-capacity battery, which not only satisfies the power consumption of the tool cart base, but also supplies power to the vehicle tools, management computers and other equipment.

The middle layer is equipped with intelligent management tool warehouse, management computer and related interface equipment, several management tool warehouse storage warehouses, designed to store two maintenance notebook computers, optical power tester, channel error tester, multimeter, cable finder, network cable pliers, crimping tools, various types of pliers, screwdrivers, etc. The upper layer of the tool cart is a work console, and the work surface is designed as a self-suction cleaning tabletop.

The tabletop cleaning hole is designed with a diameter of $3 \mathrm{~mm}$, which can suck small threads.Arrange electric soldering iron storage rack, 2M cable Q9 head welding bracket, automatic tracking camera bracket, etc.Auxiliary equipment mainly includes: network cameras, switches, 4G modules, voice modules, hidden desks, trash cans, etc.

In terms of size design, the intelligent companion tool cart must walk between the screen cabinets in the machine room. Considering the distance between the two rows of screen cabinets in the machine room is $1.2 \mathrm{~m}$, the maximum length and width of the upper working tabletop of the tool cart should not exceed $0.7 \mathrm{~m}$, which can satisfy the vehicles passing by simultaneously. The upper part of the tool cart is the operating table. In order to ensure a reasonable sitting posture, the height of the cart should not exceed $0.7 \mathrm{~m}$. The side-opening tool warehouse is adopted, and the layout of the tool warehouse is reasonably designed to ensure a reasonable height of the working desk. The physical structure of the tool cart is shown in the figure 1 .

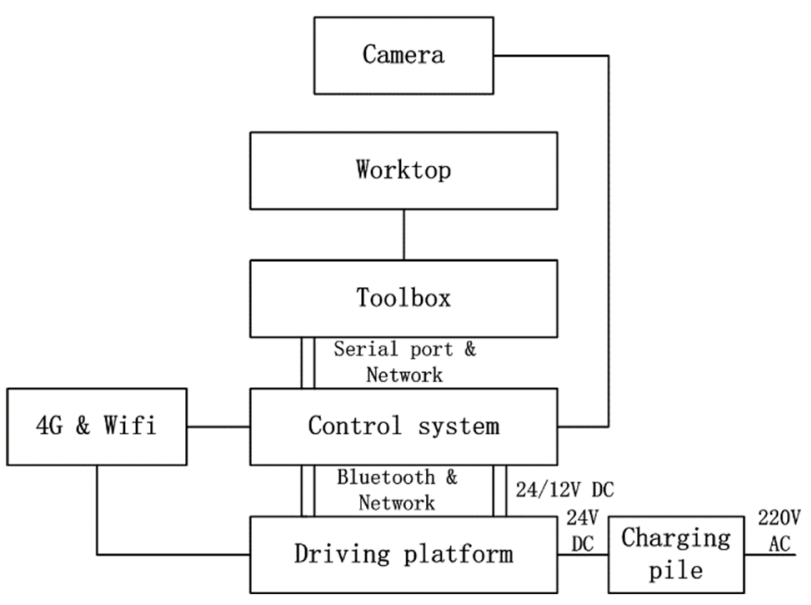

Fig. 1. Physical structure of the toolbox.

\subsection{Research on sensor and interface design}

In order to realize the function of the intelligent companion tool cart, different sensors need to be designed and installed to collect all kinds of information.

First of all, in order to achieve the environmental monitoring requirements of the tool cart, the tool cart is 
required to collect the ambient temperature and humidity in real time. Therefore, temperature and humidity sensors and cameras need to be installed. At the same time, in order to promptly warn of fire hazards in the machine room, an oxygen content sensor should be installed in the companion tool cart.

Secondly, in order to realize the patrol requirements of the tool cart, the tool cart is required to record the state of the equipment in the machine room and have the automatic movement function of navigation. Therefore, infrared and radar sensors need to be installed. At the same time, it is equipped with ultrasonic sensors and laser sensors for distance measurement and obstacle avoidance, and a tracking camera is configured to collect portrait tracking.

On the basis of sensor design, in order to lay a good foundation for subsequent software design, the system control software should be installed on the system control host, and the control host software communicates with each device through the interface software. Therefore, design the interface types and interface protocols of each function as shown in the table 1 .

Table 1. Interface design.

\begin{tabular}{|c|c|c|}
\hline Navigation interface & $\begin{array}{c}\text { Type of } \\
\text { interface }\end{array}$ & Interface Protocol \\
\hline network & smart-ap2.0 \\
\hline Tool scan interface & Serial port & JRV43 \\
\hline Touch control interface & Serial port & dwin5.2x \\
\hline $\begin{array}{c}\text { Video control interface } \\
\text { local area } \\
\text { network }\end{array}$ & Haikang-415 \\
\hline $\begin{array}{c}\text { Cloud data interface } \\
\text { Operation and } \\
\text { maintenance record } \\
\text { audio interface }\end{array}$ & $\begin{array}{c}\text { local area } \\
\text { network }\end{array}$ & Hxyput1201 \\
\hline
\end{tabular}

\subsection{Research on Intelligent Management Box for Electronic Tools}

An important function of the intelligent companion car is the intelligent storage function of tools. The internal structure of the toolbox uses lighter aluminum alloy, the support frame material uses alloy steel, and the exterior door material uses forged iron.At the same time, in order to meet the requirements of multiple types of tools in the dispatch automation computer room, different tools are classified and processed, as shown in the table 2.

Table 2. Tool classification.

\begin{tabular}{|c|c|c|c|}
\hline $\begin{array}{c}\text { Tool } \\
\text { category }\end{array}$ & tool & $\begin{array}{c}\text { Contact } \\
\text { surfaces }\end{array}$ & Maximum area \\
\hline $\mathrm{C} 1$ & $\begin{array}{c}\text { BER tester, } \\
\text { multimeter }\end{array}$ & Lumpy & $20 \mathrm{~cm} * 20 \mathrm{~cm}( \pm$ \\
\hline
\end{tabular}

\begin{tabular}{|c|c|c|c|}
\hline $\mathrm{C} 2$ & $\begin{array}{c}\text { Crimping } \\
\text { pliers, } \\
\text { stripping } \\
\text { pliers }\end{array}$ & triangle & $\begin{array}{c}30 \mathrm{~cm} * 10 \mathrm{~cm}) \\
2 \mathrm{~cm})\end{array}$ \\
\hline $\mathrm{C} 3$ & $\begin{array}{c}\text { Wrenches, } \\
\text { knives }\end{array}$ & Strip & $\begin{array}{c}30 \mathrm{~cm} * 5 \mathrm{~cm}( \pm \\
1 \mathrm{~cm})\end{array}$ \\
\hline $\mathrm{C} 4$ & $\begin{array}{c}\text { Type } \\
\text { screwdriver }\end{array}$ & $\begin{array}{c}\text { Tubular } \\
\text { cylinder }\end{array}$ & $\begin{array}{c}20 \mathrm{~cm} * 5 \mathrm{~cm}( \pm \\
5 \mathrm{~cm})\end{array}$ \\
\hline $\mathrm{C} 5$ & $\begin{array}{c}\text { Tape, cable } \\
\text { tie, test lead, } \\
\text { screw }\end{array}$ & none & none \\
\hline \multicolumn{2}{|c|}{} \\
\hline
\end{tabular}

According to the classification of tools, the capacity of the tool box should be able to accommodate 5 types of tools, with a total number of 40 to 60 pieces. Therefore, the design of the tool cart structure is 5 floors, which store 5 types of tools, and each floor is divided into 2 rooms on the left and the right.The tool cart is a toolbox with 16 warehouses. Each warehouse is configured with hardcontact information acquisition card positions according to different tool shapes. The information of each tool storage warehouse is managed through a PLC module.Develop PLC module interface program. Provide relevant information for the management computer management software, and realize the management of the tool box by the management computer.The design of the toolbox and the card reader is shown in the figure $2 \&$ figure 3 .

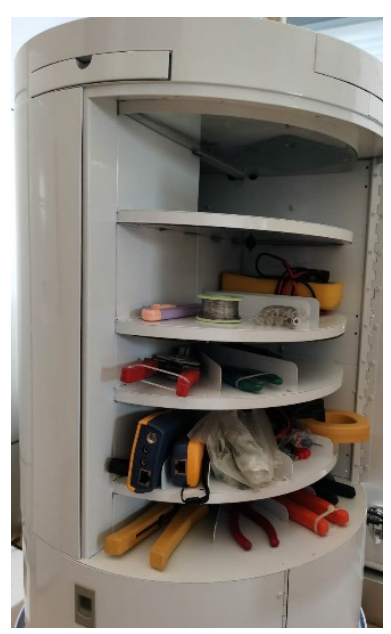

Fig. 2. Figure of Toolbox.

On this basis, in order to realize the intelligent management of tools and instruments, an electronic identification method is designed. According to the characteristics of different tools and instruments, electronic tags with unique identification codes are bound to different tools and instruments. An ultra-thin ceramic antenna is installed on the top of each tool warehouse, and the electronic tag signals are received through the antenna induction. At the same time, the antenna is connected to the radio frequency input port of the tag scanner, and the scanner is connected to the serial port of the control host, so as to transmit the electronic label signal to the control host, which is responsible for strategy scheduling or triggering real-time tag scanning. The principle of electronic tool recognition is shown in the figure 4 . 


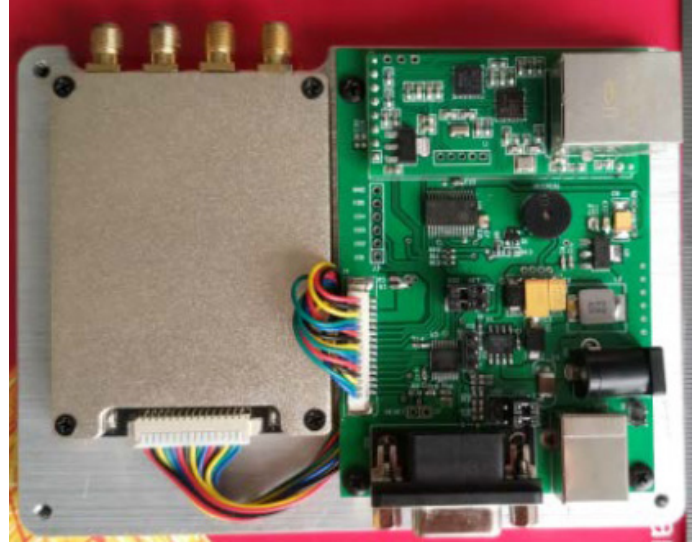

Fig. 3. Card reader.

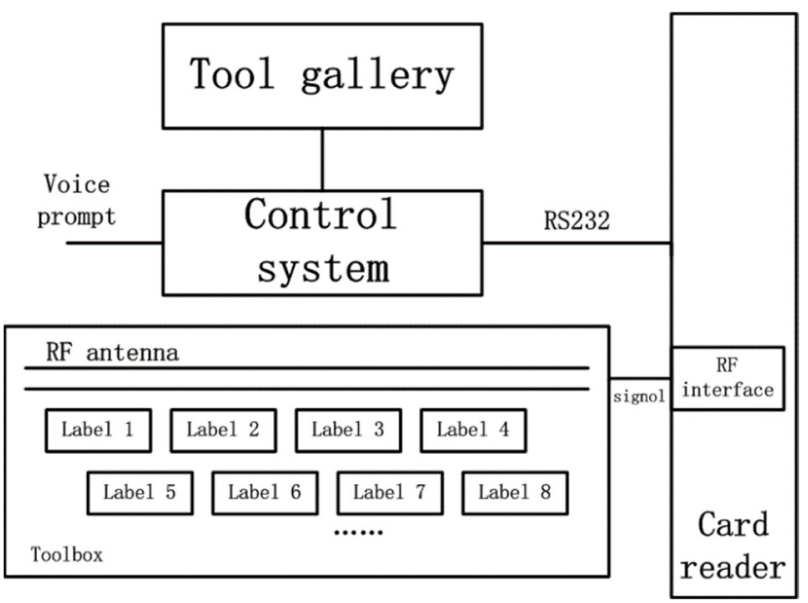

Fig. 4. Principles of electronic equipment identification

\subsection{Research on power management design}

The maintenance work time of the automated machine room is longer. In order to ensure a longer battery life of the whole machine, the hardware design actually uses a larger capacity lithium battery and is equipped with an auxiliary battery. The auxiliary battery is designed as an uninterruptible power supply, which serves as the power source for the entire control system. The auxiliary battery is charged synchronously with the main battery, sharing a charging pile. When the auxiliary battery is low, it can be automatically charged from the main battery. At the same time, the machine power supply can be used as a mobile power supply for on-site operations through transformation. The specific battery design parameters are shown in the table 3 .

Table 3. Battery parameters.

\begin{tabular}{|c|c|c|}
\hline & Main battery & Secondary battery \\
\hline $\begin{array}{c}\text { Charging } \\
\text { pile input }\end{array}$ & \multicolumn{2}{|c|}{$220 \mathrm{AC} / \mathrm{DC}$} \\
\hline $\begin{array}{c}\text { Power } \\
\text { Output }\end{array}$ & \multicolumn{2}{|c|}{$24 \mathrm{~V}(5 \mathrm{~A}) ; 12 \mathrm{~V}(2 \mathrm{~A})$} \\
\hline use & $\begin{array}{c}\text { The whole machine } \\
\text { power supply, } \\
\text { external load, and } \\
\text { can be used for step- } \\
\text { down }\end{array}$ & $\begin{array}{c}\text { Whole machine } \\
\text { control system } \\
\text { power supply }\end{array}$ \\
\hline
\end{tabular}

\begin{tabular}{|c|c|c|}
\hline capacity & $\begin{array}{c}20 \mathrm{AH}, 24 \mathrm{~V}(24- \\
27 \mathrm{~V})\end{array}$ & $\begin{array}{c}8 \mathrm{AH}, 12 \mathrm{~V}(10- \\
14 \mathrm{~V})\end{array}$ \\
\hline Endurance & $>8$ hours & $\begin{array}{c}>10 \text { hours, } \\
\text { Can be charged } \\
\text { online from the } \\
\text { main battery }\end{array}$ \\
\hline load & $\begin{array}{c}\text { Average current } \\
<2 \mathrm{~A}, \text { connected } \\
\text { equipment: } \\
\text { navigation sports } \\
\text { chassis, debugging } \\
\text { laptop, electric } \\
\text { soldering iron, etc. }\end{array}$ & $\begin{array}{c}\text { Average current } \\
<1 \mathrm{~A}, \text { connected } \\
\text { equipment: control } \\
\text { host, card reader, } \\
\text { switch, camera, } \\
\text { touch screen, etc. }\end{array}$ \\
\hline $\begin{array}{c}\text { Full charge } \\
\text { time }\end{array}$ & $<4$ hours & $<3$ hours \\
\hline $\begin{array}{c}\text { Effective } \\
\text { charging } \\
\text { times }\end{array}$ & $>2000$ times & $>1000$ times \\
\hline
\end{tabular}

\section{Conclusion}

Based on the actual problems existing in the dispatch automation computer room, the work efficiency of the computer room and the importance of the safety management of the computer room are fully considered. Therefore, the design proposes the development of an intelligent companion tool vehicle, and conducts specific research on its hardware. This article mainly studies the following contents:

According to the work requirements of the dispatch automation computer room, the overall hardware research is carried out. On this basis, the hardware research is carried out on the sensor, communication interface, tool box, and power supply. Designed RF scanning toolbox intelligent storage tools and instruments, which enhances the management of the machine room tools and reduces the staff's work preparation time. At the same time, a dual power supply structure is designed to increase the safety and reliability of the car's endurance. The research on the hardware of the intelligent companion vehicle has laid a good foundation for the software design of the subsequent intelligent companion vehicle, and at the same time provides a new idea for the management of the dispatching automation machine room.

\section{References}

1. JK Oh, AY Lee, SM Oh, Y Choi, HW Yang, Design and Control of Bridge Inspection Robot System (2007)

2. JF Shi, J Ma, HJ Zhang, etc. Development and application of integrated management platform for power dispatching automation computer room J. Ningxia Electric Power, 4, 46-51. (2017)

3. HX, Lin. Environmental monitoring system of data center. Intelligent Building and City Information, 5, 59-62. (2009)

4. EM, Zhao. Research on the motion control of intelligent inspection robots. Proceedings of the 14th Shenyang Science Conference Science, Agriculture, Medicine.1025-1028, (2017). 
5. F Li, WB Guo . Intelligent inspection technology of electric power room. Electronic Technology and Software Engineering, 12, 259-260, (2017).

6. L Hou, R Han, XX Li, etc. Application of Orbital Intelligent Inspection Robot in Daily Operation and Maintenance Inspection of Computer Room. China New Communications, 21, 107-108, (2017).

7. JJ Luo, JL Hu, YY Li, et al. Research on automatic navigation and positioning of substation inspection robot. Automation Technology and Application, 37, 88-91, (2018).

8. XL Chen. Application Analysis of Intelligent Inspection Robot in Substation. Science and Fortune, 25, 226-227, (2018).

9. DH Huang. Operation and Maintenance Analysis of Intelligent Patrol Robot System in Substation. Exploratory Science, 1, 69, (2019). 